Т.Н. Кожевникова, А.Н. Протасеня

Медицинский институт Тульского государственного университета, Российская Федерация

Возможные перспективы

использования фенспирида

в профилактических целях

у курящих школьников

Contacts:

Kozhevnikova Tat'yana Nikolaevna, MD, professor of Pediatric Department of Medical Institute of Tula State University, Honoured Doctor of RF, Head of Center of Respiratory Pathology in Children of Tula City Child Hospital № 3

Address: 52, Degtyarev Street, Tula, RF, 300052, Tel.: (4872) 47-56-17, e-mail: pulmo71@yandex.ru

Article received: 10.10.2012, Accepted for publication: 06.12.2012

Результаты эпидемиологических исследований по распространенности табакокурения позволяют рассматривать школьников средних и старших классов как потенциальную аудиторию для проведения профилактической работы по предупреждению формирования хронической обструктивной болезни легких, существенно влияющей на качество и продолжительность жизни. Среди токсических компонентов табачного дыма наиболее значимы полициклические гидрокарбонаты, оксиды азота, оксид и диоксид углерода. В настоящей работе изучено содержание оксида углерода в выдыхаемом воздухе у курящих школьников с помощью смокелайзера, и оценены возможности применения фенспирида в комплексе лечебно-профилактических мероприятий при табакокурении. Результаты исследования указывают на выраженную положительную роль фенспирида в комплексе лечебных мероприятий у курящих подростков.

Ключевые слова: табакокурение у детей и подростков, диагностика, смокелайзер, оксид углерода, лечение, фенспирид.

(Вопросы современной педиатрии. 2012; 11 (6): 110-113)

\section{ВВЕДЕНИЕ}

Эпидемиологические данные свидетельствуют о широкой распространенности хронических заболеваний легких среди курящих мужчин и женщин. По мнению различных авторов, хроническая обструктивная болезнь легких является одной из основных причин преждевременной смерти от хронических заболеваний во всем мире [1]. В течение 10-15 лет болезнь протекает бессимптомно, т.е. ее начало может приходиться на старший детский и юношеский возраст. Вместе с тем активное изучение распространенности табакокурения у детей и подростков, в т.ч. и собственные исследования, проводимые в регионе [2-4], показывают, что к пагубной привычке приобщаются даже школьники младшего возраста. Результаты проведенных эпидемиологических исследований позволяют рассматривать школьников средних и старших классов в качестве потенциальной аудитории для профилактической работы по предупреждению формирования хронической обструктивной болезни легких как заболевания, существенно влияющего на качество и продолжительность жизни.

T.N. Kozhevnikova, A.N. Protasenya

Medical Institute of the Tula State University, Russian Federation

\title{
The possible prospects of fenspiride usage in prophylaxis among school-age smokers
}

The results of epidemiologic studies on prevalence of tobacco smoking suggest that children of secondary and senior school represent a potential group for prophylaxis of chronic obstructive pulmonary disease, which has significant influence on quality and duration of life. Among the toxic components of the tobacco smoke the most important are polycyclic hydrocarbons, nitric oxides, carbon monoxide and carbon dioxide. The content of carbon monoxide in the air expired by the school-age smokers was studied with the help of smokerlyzer, the possibilities of fenspiride usage in complex medico-prophylactic measures were assessed in this study. The results of the study indicate that fenspiride has significant role in complex prophylaxis in teenage smokers.

Key words: tobacco smoking children and adolescents, diagnostics, smokerlyzer, carbon monoxide, treatment, fenspiride.

(Voprosy sovremennoi pediatrii - Current Pediatrics. 2012; 11 (6): 110-113) 
Исследования последних лет [2, 5-7] показали, что даже пассивное курение увеличивает риск развития бронхиальной гиперреактивности и бронхиальной астмы у детей.

Среди токсических компонентов табачного дыма наиболее значимы полициклические гидрокарбонаты, оксиды азота, оксид и диоксид углерода.

Широко известным механизмом биологического действия оксида углерода (СО) является образование карбоксигемоглобина ( $\mathrm{HbCO})$, при этом СО занимает место кислорода. Сродство гемоглобина $(\mathrm{Hb})$ человека к СО приблизительно в 240 раз выше, чем к кислороду: НbCO затрудняет подачу кислорода к тканям и высвобождение кислорода, доставленного молекулами Нb в ткани. CO связывается также с мышечным гемоглобином (миоглобином), что приводит к образованию карбоксимиоглобина и существенно влияет на обмен веществ в мышцах (в частности сердечной).

Однако в настоящее время известны и другие механизмы патогенного действия CO. По данным S. Soghoian и соавт. [8], растворенный в плазме крови СО, проникая в ткани, способен связываться не только с миоглобином, но и с восстановленными цитохромами, гуанилатциклазой, NO-синтетазой, что усугубляет тканевую гипоксию. Связываясь с митохондриальными цитохромами, оксид углерода блокирует цепь переноса электронов, тем самым нарушая процессы окислительного фосфорилирования и запуская процесс образования свободных радикалов.

Несмотря на то, что основным механизмом повреждающего действия оксида углерода является гипоксия, немалую роль при отравлении угарным газом играет активация воспалительных процессов в тканях организма. Воспалительные и иммуноопосредованные механизмы способствуют развитию системного воспалительного ответа. В экспериментах на животных установлено, что воздействие СО вызывает периваскулярные изменения в виде нейтрофильной инфильтрации [8]. Выделение свободных радикалов нейтрофилами активирует процесс перекисного окисления липидов, вследствие чего изменяется структура основного белка миелина и его иммунологическое распознавание, что становится причиной аутоиммунной активности против белков головного мозга.

С учетом сведений о влиянии оксида углерода на состояние сердечно-сосудистой системы, головной мозг, органы дыхания в количествах, ранее считавшихся безвредными, мы сочли необходимым исследовать состояние здоровья детей школьного возраста, подвергающихся постоянному воздействию СО на организм при курении, и оценить возможности медикаментозной коррекции курящих школьников при помощи зарекомендовавшего себя средства - фенспирида (Эреспал, Servier, Франция). В исследованиях многих авторов подтверждена возможность эффективного применения фенспирида с целью снижения бронхиальной гиперреактивности [9, 10]. Доказано, что препарат купирует проявления бронхообструктивного синдрома или предупреждает его развитие, под его влиянием снижается количество выделяемой вязкой мокроты, что связано с уменьшением образования и выделения секрета (муколитическим и отхаркивающим действием фенспирид, как известно, не обладает), а также препарат улучшает мукоцилиарный клиренс, уменьшает степень бронхиальной обструкции, делает кашель более продуктивным [9, 10].

Цель исследования: оценить содержание оксида углерода в выдыхаемом воздухе у курящих школьников с использованием смокелайзера (монитор концентрации угарного газа) и возможности применения фенспирида в комплексе лечебно-профилактических мероприятий при табакокурении.

\section{ПАЦИЕНТЫ И МЕТОДЫ}

\section{Участники исследования}

Было обследовано 47 курящих школьников 7-11 классов общеобразовательных школ г. Тулы. Среди обследуемых было 25 девочек и 22 мальчика. Средний возраст детей составил 14,4 \pm 1,05 лет. В ходе сбора анамнеза и клинического обследования пациентов было установлено, что к моменту проведения исследования 6 подростков (2 девочки и 4 мальчика) уже бросили курить, а 10 детей были в возраст менее 14 лет, что не позволило использовать у них в комплексе лечебных мероприятий исследуемый препарат в таблетированной форме.

Методом случайной выборки было определено 2 группы наблюдаемых. Первая группа $(n=17)$ получала фенспирид в дозе 80 мг 2 раза в день в течение 12 нед, вторая группа $(n=14)$ использовала симптоматическую терапию (муколитики, мукорегуляторы, отхаркивающие средства, витамины).

Основанием для включения в исследование были следующие факторы:

- наличие ежедневного кашля;

- жалобы, характеризующие признаки эндогенной интоксикации (быстрая утомляемость, головные боли, диспептические жалобы, нарушение толерантности к физической нагрузке, частые респираторные заболевания);

- функциональные признаки гиперреактивности бронхов;

- повышенный уровень содержания СО в выдыхаемом воздухе (более 11 ppm - parts per million);

- отсутствие указаний на бронхиальную астму в анамнезе.

Критерием исключения считали проявления острого респираторного заболевания на момент исследования.

\section{Методы исследования}

- Определение содержания СО в выдыхаемом воздухе с использованием смокелайзера "ріCO-Іо".

- Оценка функции внешнего дыхания (параметры регистрировали с помощью спирографа «МикроМедикал суперспиро" (Великобритания).

- По показаниям детям проводили такие исследования, как ЭКГ, ЭЭГ, Эхо-КГ, реоэнцефалография, эзофагогастродуоденоскопия, бронхофонография, консультации специалистов.

\section{Статистическая обработка данных}

Статистический анализ результатов исследования проведен с помощью пакета программ, интегрированных в Microsoft Excel 2003. 
Количественные признаки представлены в виде среднего арифметического значения \pm стандартное отклонение (M $\pm \mathrm{SD})$, дискретные признаки - в виде частот (процент наблюдений к общему числу обследованных). Сравнение количественных показателей в группах осуществлялось посредством $t$-критерия Стьюдента для независимых выборок. Различия считали статистически значимыми при $p<0,05$.

\section{РЕЗУЛЬТАТЫ}

Для оценки результатов исследования использовали следующие критерии оценки концентрации СО в выдыхаемом воздухе (табл. 1).

Исследование содержания СО в выдыхаемом воздухе проводили у курящих школьников (47 человек) по сравнению с некурящими (40 человек) и никогда не пробовавшими курить школьниками (40 человек).

Средняя концентрация СО в выдыхаемом воздухе в группе курящих школьников была равна 13,6 \pm 6,1рpm. Распределение показателей содержания СО в этой группе выглядело следующим образом: < 7 ppm - у 18,4\% курящих школьников, 7-10-у 8\%, 11-20 - у 52,7\%, > 20 - у 26,3\%. Таким образом, почти $80 \%$ школьников выкуривали около пачки сигарет в день.

Возраст некурящих школьников составил 14,7 \pm 1,0 лет. Средняя концентрация СО в выдыхаемом воздухе в группе некурящих была равна 1,8 \pm 0,83 ppm. Все дети этой группы имели концентрацию угарного газа в выдыхаемом воздухе менее 7 ppm.

Результаты клинического обследования курящих школьников позволили установить, что среди них 46\% имеют соматические заболевания. В структуре заболеваний по группам первое место заняла вегетососудистая дистония, затем хронические заболевания носоглотки, аллергический ринит, гастродуодениты.

Комплекс мероприятий включал индивидуальные беседы с детьми, оздоровительную физкультуру на базе отделения восстановительного лечения детской поликлиники по месту жительства.

Оценку эффективности лечения фенспиридом выполняли под контролем клинических симптомов, содержания СО в выдыхаемом воздухе, функции внешнего дыхания. Оценивали объем форсированного выдоха за первую секунду $\left(0 Ф \mathrm{~B}_{1}\right)$, форсированную жизненную емкость легких (ФЖЕЛ), индекс Тифно. По показаниям проводили бронхофонографию.

Продолжительность курса лечения составила 12 нед, пациенты первой группы получали фенспирид в дозе 80 мг 2 раза в день. Наблюдение пациентов проводилось с интервалом 4 нед (3 визита). Во время 2-го и 3-го визитов выполняли оценку клинического состояния ребенка, во время 3-го визита изучали содержание СО в выдыхаемом воздухе и оценивали функции внешнего дыхания. Нежелательных эффектов за время лечения фенспиридом не зарегистрировано.

К моменту окончания лечения в группе пациентов, получавших изучаемый препарат, имело место снижение степени выраженности проявлений гиперреактивности бронхов: стал менее выражен кашель, исчезла одышка при физической нагрузке; 3 детей перестали курить; в группе детей, выкуривающих более 1 пачки в сут, появилась тенденция к значительному снижению числа выкуриваемых сигарет (от 5 до 10 штук в день вместо 20). Соответственно снизились показатели СО в выдыхаемом воздухе, изменился качественный состав в группах сравнения по концентрации СО в выдыхаемом воздухе.

Средняя концентрация СО в выдыхаемом воздухе в группе курящих школьников, получавших фенспирид, до лечения составила 17,6 \pm 3,8 ppm, 70\% школьников имели концентрацию СО в диапазоне 11-20рpm и $30 \%$ - более 20 рpm.

После лечения концентрация СО в первой группе снизилась до 13,3 \pm 3,2 ppm, качественные изменения по концентрации СО характеризовались уменьшением

Таблица 1. Критерии оценки концентрации СО в выдыхаемом воздухе

\begin{tabular}{|c|c|}
\hline Концентрация Со, ppm & Категории пациентов \\
\hline$<5$ & Некурящие, проживающие в экологически благоприятном районе \\
\hline $5-6$ & Некурящие, проживающие в индустриально развитом районе \\
\hline $7-10$ & Некурящие, подвергающиеся пассивному курению \\
\hline $11-20$ & Курящие, 8-15 сигарет в день \\
\hline$>20$ & Курящие, 20 и более сигарет в день \\
\hline
\end{tabular}

Примечание. СО — оксид углерода, ppm — parts per million (частей на млн).

Таблица 2. Динамика показателей концентрации оксида углерода в выдыхаемом воздухе у курящих школьников на фоне приема фенспирида

\begin{tabular}{|l|c|c|}
\hline \multicolumn{1}{|c|}{ Группы наблюдения } & $\begin{array}{c}\text { Показатели со } \\
\text { до лечения, ppm }\end{array}$ & $\begin{array}{c}\text { Показатели со } \\
\text { после лечения, ррт }\end{array}$ \\
\hline Группа 1 (дети, получающие фенспирид, $n=17)$ & $17,6 \pm 3,8$ & $13,3 \pm 3,2$ \\
\hline Группа 2 (группа сравнения, $n=14)$ & $16,8 \pm 2,9$ & $15,9 \pm 2,7$ \\
\hline
\end{tabular}

Примечание. СO - оксид углерода, ppm — parts per million. Данные представлены в виде M \pm SD. 
числа курящих школьников, имеющих концентрацию СО более 20 ррm, до 23,4\%.

В то же время в группе сравнения у курящих школьников, лечившихся симптоматически, подобных изменений не отмечалось. Средняя концентрация СО в выдыхаемом воздухе в этой группе детей до лечения составила $16,8 \pm 2,9$ ppm (табл. 2). Распределение наблюдаемых по содержанию СО в выдыхаемом воздухе в этой группе выглядело следующим образом: от 11 до 20 рpm - у 73\% детей, более 20 ppm - у 27\% школьников. После курса симптоматической терапии существенных изменений зарегистрировано не было. Концентрация СО в выдыхаемом воздухе после лечения была равна 15,9 \pm 2,7 ppm. Никто из пациентов не бросил курить, но 5 детей, по данным опроса, задумались о вреде курения и планировали сократить число выкуриваемых сигарет.

Изучение функции внешнего дыхания в первой группе (на фоне лечения фенспиридом) выявило тенденцию к повышению ОФВ стически недостоверным.

\section{ЗАКЛЮЧЕНИЕ}

Результаты исследования указывают на существенную положительную роль фенспирида в комплексе лечебных мероприятий у курящих подростков в уменьшении концентрации таких токсических веществ, как оксид углерода, который вызывает активацию воспалительных процессов в тканях организма.

Многочисленные исследования последних лет, указывающие на выраженный противовоспалительный эффект фенспирида, свидетельствуют о целесообразности применения этого препарата на ранних стадиях развития хронической обструктивной болезни легких, предиктором которой, безусловно, является курение. Это позволяет рекомендовать фенспирид в качестве препарата базисного лечения у курящих школьников.

\section{REFERENCES}

1. Profilaktika tabakokureniya u detei i podrostkov. Rukovodstvo dlya vrachei. Pod red. prof. N.A. Geppe [Tobacco Prevention in Children and Adolescent. Guideline. Edited by N. A. Geppe]. Moscow, GEOTAR-Media, 2008.

2. Kozhevnikova T. N. Opyt raboty Gorodskogo tsentra respiratornoi patologii u detei po profilaktike tabakokureniya. Pul'monologiya detskogo vozrasta: problemy i resheniya. Pod red. Yu. L. Mizernitskogo, A.D. Tsaregorodtseva, vyp. 11 [Experience of City Center of Respiratory Pathology in Children in Tobacco Prevention. Pediatric Pulmonology: Problems and Solutions. Edited by Yu.L. Mizernitskii, A.D. Tsaregorodtsev, 11th edition]. Moscow, Medpraktika-M, 2011. pp. 274-279.

3. Skvortsova E.S., Zubkova N.Z. Profilaktika zabolevanii i ukreplenie zdorov'ya - Disease prevention and health promotion. 2005; 1: 26-30.

4. Myskina O.A., Pipiya N.G., Kozhevnikova T.N. Vestn. novykh meditsinskikh tekhnologii - Bulletin of current medical innovations. 2009; KhVI (2): 124-126.

5. Alenina E. D., Protasenya A. N., Kozhevnikova T. N. Vestn. novykh meditsinskikh tekhnologii - Bulletin of current medical innovations. 2009; KhVI (2): 6-9.

6. Nats. progr. "Bronkhial'naya astma u detei. Strategiya lecheniya $i$ profilaktika". 4-e izd., ispravl. i dop [National Programme "Bronchial Asthma in Children. Strategy of Treatment and Prevention" 4th Edition, revised and enlarged]. Moscow, 2012. pp. 31-40.

7. Moshammer H., Hoec Q., Luttmann-Qibson H. et al. Parental smoking and lunq function in children: an international study. Am. J. Respir. Crit. Care Med. 2006; 173: 1255-1263.

8. Thom S.R., Bhopale V.M., Fisher D., Zhang J., Gimotty P., Forster R.E. Carbon monoxide poisoning is immune-mediated. Proceedings of the National Academy of Sciences of the United States of America. 2004; 101 (37): 13660-13665.

9. Shmelev E.I. Zdorov'e Ukrainy - Ukranian health. 2008; 22 (1): 16-17.

10. Bezlepko A. V., Bezlepko E.A., Zakharova N.K., Efimova V.E. Pul'monologiya - Pulmonology. 2009; 4: 85-90. 